\title{
An optimisation of the hybrid renewable energy systems
}

\author{
Marek Jaszczur ${ }^{1, *}$, Qusay Hassan ${ }^{2}$, and Patryk Palej ${ }^{1}$ \\ ${ }^{1}$ AGH University of Science and Technology, Department of Fuels and Energy, Poland \\ ${ }^{2}$ University of Diyala, Department of Mechanical Engineering, Iraq
}

\begin{abstract}
In this work, we focus on utilization of hybrid renewable energy system for a residential load based in two different optimisation criteria. The presented system utilises photovoltaic modules wind turbines and batteries as energy storage. The analyses were carried out based on experimental measurements, for the electrical load, local solar radiation, wind speed and other environmental parameters. The optimisation process has been performed based on two aspects economic and ecological. The novelty of this work to find the relationship between two optimisation objectives.
\end{abstract}

\section{Introduction}

Growing usage of energy in the present days is a challenge for the energy sector. The larger and larger part of our lives depends on continuous access to electricity. Therefore, increasing power generation and distribution reliability are highly required. In the era of energy safety consciousness, facing running out of fossil fuels and growing natural environment pollution, we are looking for new alternatives. Among the renewable energy resources, wind and solar are the most promising resources and widely available. Single sources renewable energy system can be designed as a grid-connected or standalone, but the reliability of dispatch and efficiency of these systems are lower due to the stochastic nature of these resources. For this reason, Hybrid Renewable Energy System (HRES) can be a partial solution to this problem. Hybrid renewable energy systems connected with traditional power suppliers are an attractive technological solution in the field of energy engineering. It integrates a few energy resources. Additionally, coupling such a system with the grid allows for reliable operation and guarantees an uninterrupted power supply. Currently, a large number of research studies has been done for HRES modelling at different sites. A review for utilizes HRES has been prepared in [1]. Bhandari et al. [2] have been investigated the HRES based in PV, battery and diesel generator and the optimisation objective was the cost of energy. The economics operation considering uncertainty for the HRES based on WT, PV, diesel generator and batteries as a storage unit obtained $0.19 \$ / \mathrm{kWh}$ COE was prepared by Sobu and $\mathrm{Wu}[3]$. The evolution of the PV system, the battery in grid-connected has been presented by $\mathrm{Ru}$ et al. [4]. The trend for integrating different renewable energy sources as HRES and designed to supply various outputs simultaneously has been shown in $[5,6]$. In other research studies, Abbassi et al. [7] analysed HRES based on PV, wind, battery and grid

*Corresponding author: jaszczur@agh.edu.pl 
connected. The authors used a new approach for optimising power reliability based on fluctuation renewable energy resources. Ahmadi et al. [8] muddled PV, wind, battery offgrid HRES and optimised based on the economical objective. Hassan et al. [9] analysed HRES based on solar and wind combined with the diesel generator for rural area electrification. The technical and economic analysis for the model has been performed. The diesel generator is vital for the project as it allows to meet the power demand when energy from renewable sources is low. The results show that the power generated from that system meets the desired load at a cost about $(\$ 0.321 / \mathrm{kWh})$. In [10] a PV-Grid energy system has been designed and analysed to feed the required energy for single housed based on the experimental metrological data. The economic aspect was considered in addition to the $\mathrm{CO}_{2}$ emissions reduction based on renewable energy generated from renewables. The results estimate the cost for $1 \mathrm{kWh}$ of electrical energy by about $\$ 0.51$ and the average of $\mathrm{CO}_{2}$ emissions avoidance by about $1840 \mathrm{~kg} /$ year compared with conventionally used in that site. The energy degradation due to the natural dust deposition on the PV module was studied by Jaszczur et al. [11] and Styszko et al. [12]. They estimated time characteristics of dust deposition distribution as well as its influence on energy production and efficiency loss. Ceran et al. [13] modelled HRES based on wind turbines, photovoltaic modules and fuel cells combined to supply different electrical loads. The results based on the economic objective and showed the optimum configuration confirm the effectiveness of the proposed approach that can serve the desired load. A different strategy for power flow control in PV-wind hybrid system is discussed by Arul et al. [14]. The results show that the interfacing energy conversion strategy and the correspondence of devices during the power producing period is very crucial for the hybrid power system analysis. A different methodology for HRES optimisation was studied by Al-Falahi et al. [15]. The study compares modern techniques, software tools and classical algorithms for HRES sizing. The results show that modern methods are more accurate than software tools and traditional algorithms for solving optimisation problems. Review for the power generated from the hybrid power system has been prepared by Balleh et al. [16]. The study also analysed the quantity and profitability of power production of that energy supply systems. Hiendro et al. [17] used HOMER software for the techno-economic feasibility analysis of the hybrid energy system. The study investigated the use of the potential wind and solar energies for the PV-wind hybrid power system in on-grid/off-grid scenarios. In the last decades, different renewable energy systems were proposed and hybridised for different configurations. In [18] HRES are reviewed in term of systems modelling, sizing and control methodologies as well as optimisation. An additional review of HRES was conducted by Jahangiri et al. [19].

The above reviews show that most of the system analyses are based on the optimisation of energy generated for the single objective. In this work, the focus is on the utilisation of HRES using two objectives of optimisations economical and ecological. The proposed initial system is a combination of two renewable energy sources with a storage unit. The aim is to obtain the relationship between optimisation objectives for better HRES design.

\section{Experimental data and system description}

Load demand: The sources of the electrical load considered in this analysis base on experimental measurement for a household in Krakow, Poland at high one-minute time step resolution for the period of 1.01.2017-31.12.2017. The daily load for two selected days and monthly energy consumption are presented in Figs.1(a)-(b) respectively.

Solar radiation: For evaluate the power generation from PV component, the global and diffused components of solar radiation were measured by pyranometers located at the AGH University of Science and Technology, Kraków, Poland. Experimental data were recorded for the whole year 2017, Fig. 2 (a) shows the incident solar radiation for two days sunny. 
Wind speed and ambient: The weather data has been acquired from the weather meters located at AGH University of Science and Technology for the period 01.01.2017- 31.12.017. The measured data was acquired at 300s time step and are presented in Fig. 2(b).
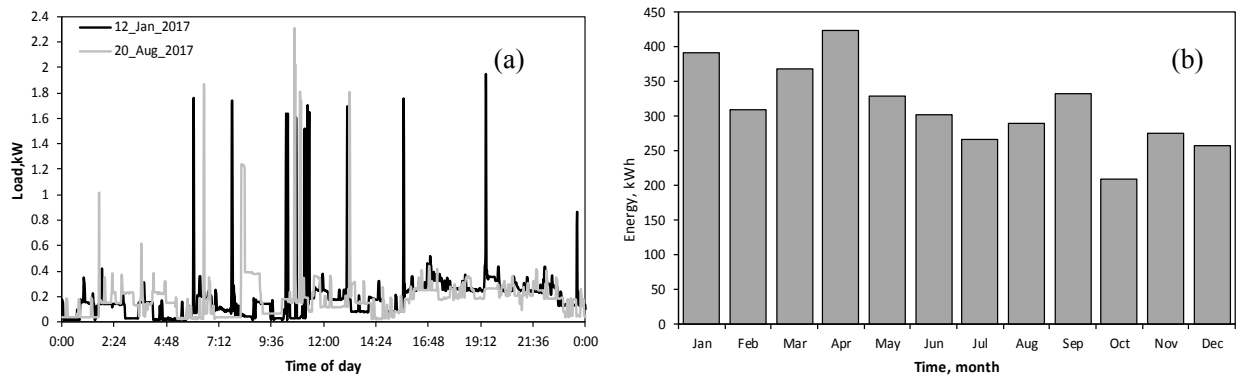

Fig. 1. Instantaneous electrical load (a) and monthly averaged electrical energy consumption (b).
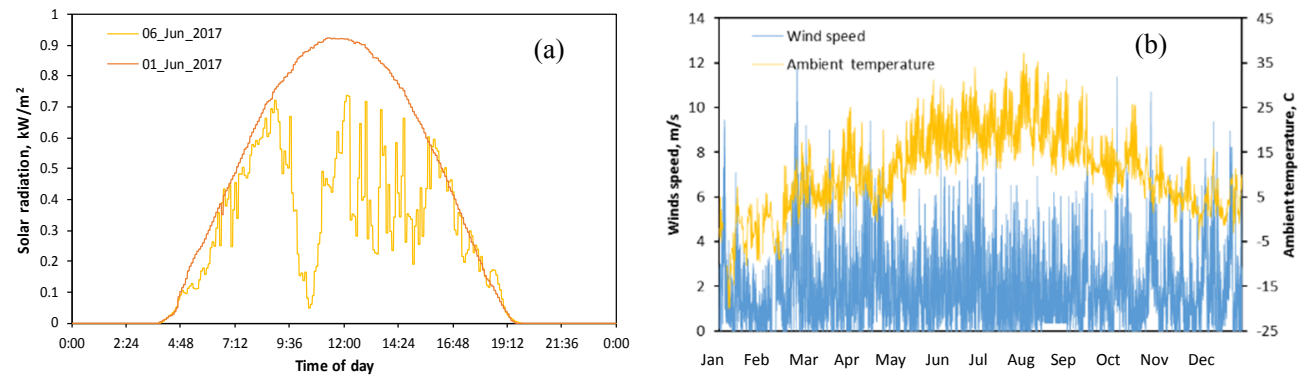

Fig. 2. Incident solar radiation (a), wind speed and ambient temperature (b).

Hybrid energy system scenario: The HRES consists of PV system, wind turbine and storage unit connected to the grid. The temporary power shortages associated with the stochastic nature of the energy generated by renewable sources is compensated by the energy from the batteries or grid system. System power balancing depends on the ratio of power generated by renewable energy sources to the energy load.

The instantaneous power generated from the system can be described by the following equations. Where the total power generated by HRES can be described as follows:

$$
\boldsymbol{P}_{h, t}=\boldsymbol{P}_{W T, t}+\boldsymbol{P}_{P V, t}+\boldsymbol{P}_{b, t}+\boldsymbol{P}_{G r i d, t}[\mathrm{~kW}]
$$

where $P_{h, t}$ is the power of the HRES, $P_{b, t}$ is power stored in the battery $P_{W T, t}$ is the power generated by a wind turbine and $P_{P V, t}$ is the power generated by PV panels. $P_{P V}$ and $P_{W T}$ can be calculated from the following equations $[20,21]$ :

$$
P_{P V}=C . G \cdot T \cdot \eta[\mathrm{kW}] \quad P_{W T}=\frac{1}{2} \cdot v^{3} \cdot \rho \cdot A \cdot \eta[\mathrm{kW}]
$$

where $C$ is the rated capacity of the PV module, $T$ is the PV module instantaneous temperature, $G$ is incident solar radiation, $\eta$ is the efficiency of energy conversion, $v$ is wind speed, $\rho$ is air density, $A$ is area of the rotor. The optimisation process has been done using two different criteria: economical and environmental. The economical optimisation based on minimizing the total NPC and the COE. The COE can be calculated as follows:

$$
C O E=\frac{C_{a n n, t o t}}{E_{\text {prim }, A C, D C}+E_{\text {grid }, \text { sales }}}
$$

where $E_{\text {prim, } A C, D C}$ is the $\mathrm{AC}$ and DC primary load, $E_{\text {grid,sales }}$ is the energy sell to the grid and $C_{a n n, t o t}$ is the annual cost of the system that includes the annualised costs of the renewable system component. The NPC can be calculated as follows: 


$$
C_{N P C}=\frac{C_{a n n, t o t}}{C R F\left(i, R_{\text {proj }}\right)} \quad \operatorname{CRF}(i, N)=\frac{i(1+i)^{N}}{(1+i)^{N}-1}
$$

where $i$ stands for interest rate and $N$ is the number of years of the system exploitation.

The environmental optimisation based on minimizing the $\mathrm{CO}_{2}$ emissions which consist the of $\mathrm{CO}_{2}$ emissions generated due to the energy taken from the grid (depends on the fuel type in the power station) and emissions due to the system components manufacturing process:

$$
\mathrm{HRES}_{\mathrm{co}_{2}}=\mathrm{PV}_{\mathrm{Co}_{2}}+W \mathrm{~W}_{c o_{2}}+\text { Battery }_{\mathrm{co}_{2}}+\text { Inverter }_{\mathrm{co}_{2}}+\text { Grid }_{c o_{2}}
$$

where $\mathrm{HRES}_{\mathrm{CO} 2}$ is the total $\mathrm{CO}_{2}$ emissions generated for HRES $(\mathrm{kg}), P V_{\mathrm{CO} 2}, W_{\mathrm{CO} 2}$, Battery $\mathrm{CO}_{2}$ are the $\mathrm{CO}_{2}$ emissions generated due to manufacturing process of PV, WT or Battery component respectively $(\mathrm{kg})$ and $\mathrm{Grid}_{\mathrm{CO} 2}$ is the $\mathrm{CO}_{2}$ emissions generated due energy taken from Grid (kg). The components and constraints are shown in Table 1.

Table 1. System components data used for the optimisation.

\begin{tabular}{|l|l|l|l|}
\hline Parameter & Specific cost & Lifetime & Refs./Comment \\
\hline Wind turbine & $300(€ / \mathrm{unit})$ & $25 \mathrm{yr}$ & Aeolos-H $1 \mathrm{KW}, \mathrm{CO}_{2}$ emissions $300 \mathrm{~kg} / \mathrm{kW}$ \\
\hline Photovoltaic module & $220(€ / \mathrm{kW})$ & $25 \mathrm{yr}$ & Schott ASI200, $\mathrm{CO}_{2}$ emissions $800 \mathrm{~kg} / \mathrm{kWp}$ \\
\hline Battery & $300(€ / \mathrm{kWh})$ & $35000 \mathrm{~h}$ & OPZS-Hawker: TLS3, $\mathrm{CO}_{2}$ emissions $55 \mathrm{~kg} / \mathrm{kWh}$ \\
\hline Inverter & $2000(€ / \mathrm{kWh})$ & $10 \mathrm{yr}$ & Generic: $1200 \mathrm{CH}, \mathrm{CO}_{2}$ emissions $60 \mathrm{~kg} / \mathrm{kW}$ \\
\hline
\end{tabular}

The amount of $\mathrm{CO}_{2}$ emission for the energy generated from power station based on selected type of fuel considered is $0.4 \mathrm{kgCO}_{2} / \mathrm{kWh}$. The project lifetime is 25 years and the annual discount rate is $2 \%$, annual inflation $2 \%$ and interesting nominal rate of $4 \%$. The prices for grid energy based on prices for 2017 in Poland for energy purchases $0.146 € / \mathrm{kWh}$, energy sell $0.117 € / \mathrm{kWh}$. The $\mathrm{CO}_{2}$ emission for electrical grid system energy is $0.867 \mathrm{~kg} / \mathrm{kWh}[12]$.

\section{Results}

The analysis performed in this work are based on grid-connected systems and optimised using two objectives, economic objective and ecological objective (minimise $\mathrm{CO}_{2}$ emissions). The economic objective results for the renewable energy sources and after several numerical iterations listed the most optimised results of systems configurations. The five top system configurations are listed in Table 2 (a). On the other hand, based on the environmental objective optimised results of systems configurations for five top system configurations are shown in Table 2 (b).

Figures 3 (a)-(b) shown the instantaneous power distribution for the sunny day (04.10.2017) at two objectives of optimisation economical and ecological respectively and based on the best configuration that is shown in Table 2(a)-(b) at a one-minute simulation time step.

Table 2(a). Optimised HRES configuration based on economic optimisation objective.

\begin{tabular}{|c|c|c|c|c|c|c|c|c|}
\hline No. & $\begin{array}{c}\text { Total Net } \\
\text { Present Cost } \\
(\boldsymbol{\epsilon})\end{array}$ & $\mathbf{C O E}(\boldsymbol{\epsilon})$ & $\begin{array}{c}\mathbf{C O}_{2} \\
(\mathbf{k g} / \mathbf{y r})\end{array}$ & PV (kW) & WT (kW) & $\begin{array}{c}\text { Battery } \\
(\mathbf{k W h})\end{array}$ & $\begin{array}{c}\text { Renewable } \\
\mathbf{e n e r g y} \\
(\mathbf{k W h} / \mathbf{y r})\end{array}$ & $\begin{array}{c}\text { Excess } \\
\mathbf{( k W h} / \mathbf{y r})\end{array}$ \\
\hline $\mathbf{1}$ & 28267.3 & 0.3 & 2263.12 & 4.2 & 1.26 & 8.64 & 4374 & 2775 \\
\hline $\mathbf{2}$ & 28428.9 & 0.3 & 2255.49 & 4.2 & 2.578 & 8.64 & 4500 & 2856 \\
\hline $\mathbf{3}$ & 28636.9 & 0.31 & 2249.64 & 4.5 & 1.26 & 8.64 & 4673 & 3045 \\
\hline $\mathbf{4}$ & 28801.2 & 0.31 & 2242.84 & 4.5 & 2.578 & 8.64 & 4798 & 3127 \\
\hline $\mathbf{5}$ & 29012.2 & 0.31 & 2237.88 & 4.8 & 1.26 & 8.64 & 4971 & 3317 \\
\hline
\end{tabular}


Table 2(b). Optimised HRES configuration based on environmental optimisation objective.

\begin{tabular}{|c|c|c|c|c|c|c|c|c|}
\hline No. & $\begin{array}{c}\text { Total Net } \\
\text { Present } \\
\text { Cost }(\boldsymbol{\epsilon})\end{array}$ & COE $(\boldsymbol{\epsilon})$ & $\begin{array}{c}\mathbf{C O} \\
(\mathbf{k g} / \mathbf{y r})\end{array}$ & PV (kW) & WT (kW) & $\begin{array}{c}\text { Battery } \\
(\mathbf{k W h})\end{array}$ & $\begin{array}{c}\text { Renewable } \\
\text { energy } \\
(\mathbf{k W h} / \mathbf{y r})\end{array}$ & $\begin{array}{c}\text { Excess } \\
(\mathbf{k W h} / \mathbf{y r})\end{array}$ \\
\hline $\mathbf{1}$ & 42267.7 & 0.45 & 2131.1 & 7.2 & 11.34 & 8.64 & 8895 & 6924 \\
\hline $\mathbf{2}$ & 40980.9 & 0.44 & 2151.2 & 7.2 & 10.08 & 8.64 & 8704 & 6748 \\
\hline $\mathbf{3}$ & 39697.3 & 0.42 & 2162.3 & 7.2 & 8.82 & 8.64 & 8512 & 6570 \\
\hline $\mathbf{4}$ & 38420.3 & 0.41 & 2175.3 & 7.2 & 7.56 & 8.64 & 8320 & 6394 \\
\hline $\mathbf{5}$ & 37149.1 & 0.4 & 2180.1 & 7.2 & 6.3 & 8.64 & 8128 & 6218 \\
\hline
\end{tabular}
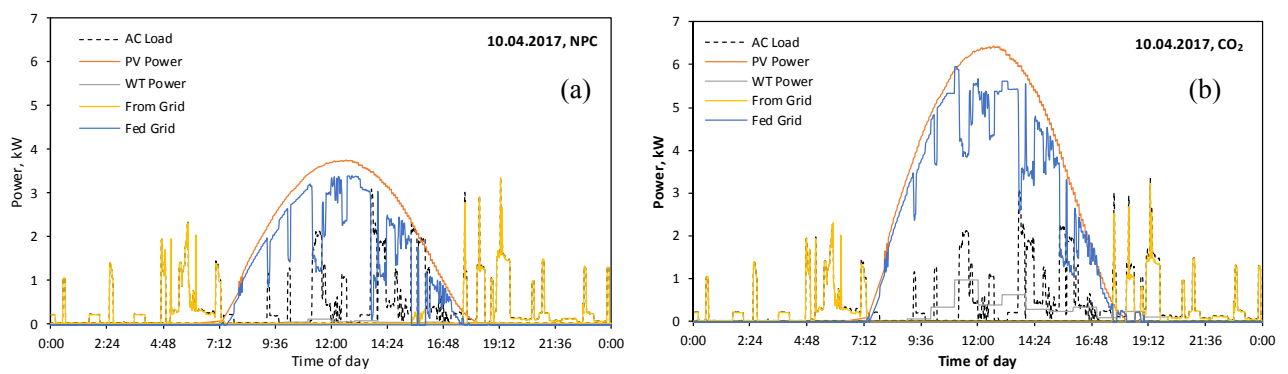

Fig. 3.The daily energy flows for the sunny day and the economical(a) and environmental(b) objectives.
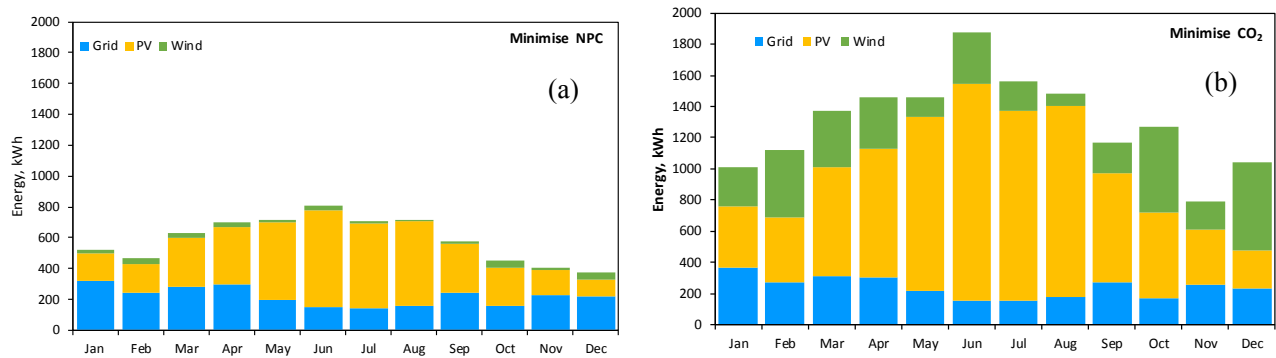

Fig. 4. The monthly energy consumption from the grid and energy generated for best HRES for economic optimisation objective (a) and environmental optimisation objectives (b).

Figures 4 (a)-(b) shows the monthly energy generated by HRES best configurations from Table 2 (a)-(b) based on two objectives of optimisation. The yearly renewable energy recorded base on environmental objective for PV is $7079 \mathrm{kWh} / \mathrm{yr}$, and for WT is 2783 $\mathrm{kWh} / \mathrm{yr}$, while base on economical objective, PV production is $4130 \mathrm{kWh} / \mathrm{yr}$, while WT only $309 \mathrm{kWh} / \mathrm{yr}$. It is clear that the environmental objective has higher renewable energy production than economic objective and that leads to reduce the energy taken from the grid as well as minimise $\mathrm{CO}_{2}$ emissions.

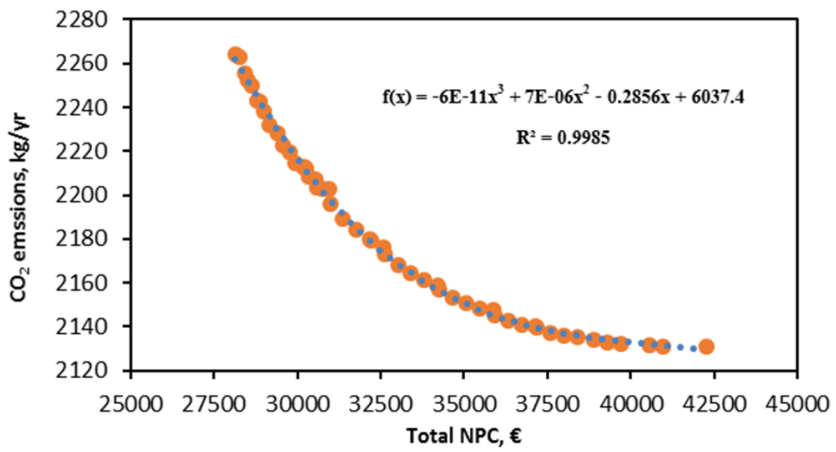

Fig. 5. The relations between two optimisation objectives $-\mathrm{CO}_{2}$ emission and net present cost NPC. 
Figure 5 shows the relationship between the environmental and economical objectives. It is shown that high investment in renewable energy components reduces $\mathrm{CO}_{2}$ emission due to higher energy generation, however, $\mathrm{CO}_{2}$ emission decrease is in this case very low in referent to NPC increase.

\section{Conclusions}

The HRES optimisation is a very powerful tool for system design and optimal configuration selection as well as allows to find the system which meets the specified design criteria. Determining the optimum configuration in order to get the highest economical in environmental benefit is the major challenges for the researchers. In this works a comprehensive dynamic simulation for HRES evaluation under two optimisation objectives economic and environmental were done. For the selected site, the optimisation procedure shows that the low wind energy impacts the system while the photovoltaic modules show better alternatives. The economic and environmental analysis contains the relationship between system $\mathrm{NPC}$ and $\mathrm{CO}_{2}$ emissions under renewable energy reliability and penetration for on-grid energy systems, were with the multicriteria optimisation it is possible to find the optimal solution for the system meeting and for the given conditions.

ACKNOWLEDGMENTS This work was supported by the Polish Ministry of Science (Grant AGH No. 16.16.210.476).

\section{References}

1. S. Guo, Q. Liu, J. Sun, H. Jin, Renew Sust Energ Rev. 91, 1121 (2018)

2. Y. Bhandari, S. Chalise, J. Sternhagen, R. Tonkoski, IEEE Int. Conf. EIT 1 (2013)

3. A. Sobu, G. Wu, IEEE PES Innovative Smart Grid Technologies 1 (2012)

4. Y. Ru, J. Kleissl, S. Martinez, IEEE Transactions on sustainable energy, 4, 68 (2012)

5. R. Sharma, V. Goyal, $2^{\text {nd }}$ Int. Conf INDIACom, 1201 (2015)

6. S. Singh, M. Singh, S. C. Kaushik, Energy Conv. Manag. 128, 178 (2016)

7. A. Abbassi, M. A, Dami, M. Jemli, Renewable Energy, 103, 81 (2017)

8. S. Ahmadi, S. Abdi, Solar Energy, 134, 366 (2016)

9. Q. Hassan, M. Jaszczur, J. Abdulateef, Jour.Phys. Conf. Ser. 745, 032006 (2016)

10. Q. Hassan, M. Jaszczur, M. Mohamed, K. Styszko, K. Szramowiat, J. Gołaś, E3S, 10, (2016)

11. M. Jaszczur, J. Teneta, K. Styszko, Q. Hassan, P. Burzyńska, E. Marcinek, N. Łopian, Environmental Science and Pollution Research, 26, 8402 (2019)

12. K. Styszko, M. Jaszczur, J. Teneta, Q. Hassan, P. Burzyńska, E. Marcinek, L. Samek, Environmental Science and Pollution Research, 26, 8393 (2019)

13. B. Ceran, Q. Hassan, M. Jaszczur, K. Sroka, E3S, 14, 01020 (2017)

14. P. Arul, V. Ramachandaramurthy, R. Rajkumar, Renew Sust Energ Rev. 42, 597 (2015)

15. M. D. Al-Falahi, S. D. G. Jayasinghe, H. Enshaei, Energy Conv. Manag. 143, 252 (2017)

16. A. Balleh, A. Faydallah, N. Moubayed, Int. ConfEPE (2016)

17. A. Hiendro, R. Kurnianto, M. Rajagukguk, Y. M. Simanjuntak, Energy, 59, 652 (2013)

18. K.S. Krishna, K.S. Kumar, Renew Sust Energ Rev. 52, 907 (2015)

19. M. Jahangiri, A. Haghani, A. Khosravi, H. A. Raeisi, Renew Sust Energ Rev. 99, 169 (2019)

20. Q. Hassan, M. Jaszczur, E. Przenzak, E3S Web of Conferences, 14, (2017)

21. Q. Hassan, M. Jaszczur, M., Serrano Juste, R. Hanus, IOP Conference Series: Earth and Environmental Science, 214, 012113 (2019) 